\title{
A case study in the Chernobyl zone Part 2: Predicting radiation induced effects in biota
}

\author{
N.A. Beresford ${ }^{1}$, S.M. Wright ${ }^{1}$, C.L. Barnett ${ }^{1}$, J .L. Hingston ${ }^{2}$, J . Vives i Batlle ${ }^{3}$,

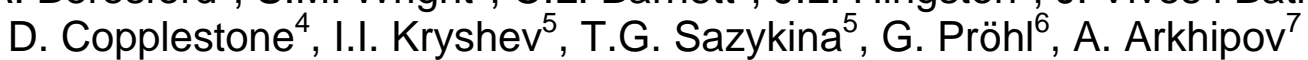 \\ and B.J. Howard ${ }^{1}$ \\ ${ }^{1}$ Centre for Ecology \& Hydrology, Lancaster Environment Centre, Library Avenue, Bailrigg, \\ Lancaster LA1 4AP, UK, e-mail: nab@ceh.ac.uk \\ ${ }^{2}$ Jones Building, School of Biological Sciences, University of Liverpool L69 3GS, UK \\ ${ }^{3}$ Westlakes Research Institute, Moor Row, Cumbria CA24 3LN, UK \\ ${ }^{4}$ Environment Agency, Richard Fairclough House, Knutsford Rd.,Warrington WA4 1HG, UK \\ ${ }^{5}$ SPA “TYPHOON", 82 Lenin Av., Obnisk, Kaluga Region 249038, Russia \\ ${ }^{6}$ GSF-National Research Center for Environment and Health, Institute of Radiation \\ Protection, 85764 Neuherberg, Germany \\ ${ }^{7}$ International Radioecology Laboratory, ICC, Post Box 151, Slavutych, \\ Kiev District 07100, Ukraine
}

\begin{abstract}
In this paper we use the FASSET framework to estimate absorbed dose rates for biota within the Chernobyl exclusion zone. The estimated doses are compared to observed biological effects within the Chernobyl exclusion zone and effects expected from summaries of existing knowledge and the extent of contamination. Although paucity of observations under conditions of chronic irradiation makes direct comparison difficult, the biological effects observed in the Chernobyl exclusion zone over the period considered here (1988-2003) are broadly in agreement with those which may have been expected.
\end{abstract}

\section{INTRODUCTION}

A number of frameworks and methodologies to assess the protection of wildlife from ionising radiations have been proposed [1-3]. Whilst some of these are now being used by national authorities [4] there has, to date, been little attempt to rigorously test their predictions against available data. In part, this is because of a lack of sites where radiation induced effects can be observed. One such site is the Chernobyl exclusion zone for which a considerable amount of data are available for a wide range of biota across a gradient of exposure rates [5]. In a separate paper we applied the methodology of the FASSET environmental impact assessment framework [3] to estimate the whole-body radiocaesium and ${ }^{90} \mathrm{Sr}$ concentrations of wild animals within the Chernobyl exclusion zone and compared these to available data for mammal and invertebrate species [6]. Predicted activity concentrations were generally within the observed ranges and mean predictions for reference organisms were similar to, or circa one order of magnitude higher than, observed means. However, a few predictions were more than one order of magnitude lower than observed values. No data were available to test predictions for other radionuclides released by the Chernobyl accident. In this paper we apply the FASSET methodology to estimate dose to terrestrial animals and plants within the Chernobyl exclusion zone. With reference to biological effects observed under conditions of chronic radiation exposure summarised in the FASSET methodology, we compare estimated doses to reported biological effects from studies within the Chernobyl exclusion zone. 


\section{THE FASSET FRAMEWORK}

Biota are represented within the FASSET framework by a range of reference organisms in seven ecosystem types. The terrestrial ecosystems considered which are most appropriate to the Chernobyl exclusion zone are semi-natural pastures and forests. The reference organisms for these ecosystems are: soil micro-organisms, soil invertebrate, burrowing mammal, carnivorous mammal, herbivorous mammal, detritivorous invertebrate, bird egg, grass/herb, shrub and tree. Radionuclides of 19 elements are considered [3]. Dose conversion coefficients (DCCs) relating radionuclide activity concentration in animal-whole-body $\left(\mu \mathrm{G} \mathrm{h}^{-1}: \mathrm{Bq} \mathrm{kg}^{-1}\right.$ fresh weight) or soil $\left(\mu \mathrm{Gy} \mathrm{h}^{-1}: \mathrm{Bq} \mathrm{kg}^{-1}\right.$ dry weight) to estimate internal and external unweighted absorbed doses are presented [7].To represent the reference organisms, DCCs are presented for geometries corresponding to: woodlouse, earthworm, mouse, mole, weasel, rabbit, red fox, roe deer and, bird eggs. For plants, only external dose rates to meristem (grass) or bud (shrubs and trees) are estimated. Concentration ratios (CR) to enable the prediction of the activity concentrations in biota from soil activity concentrations are recommended when measurements of activity concentrations in biota are not available [6,7]. To conduct this assessment, prototype software incorporating the FASSET CR and DCC values was used.

To provide a basis for radiation effects analysis within the FASSET framework, data on radiation effects were compiled; effects were grouped into the categories of morbidity, mortality, reproductive success or mutation. The available data for chronic exposure observations were summarised [3] and these are used in this assessment for comparison with estimated doses and reported biological effects.

\section{ESTIMATION OF ABSORBED DOSE RATE}

Doses were estimated using DCCs and measured activity concentrations of radionuclides in soil or biota, where possible, for independent data not utilised within the FASSET framework [5,8-13]. Where soil activity concentrations were lacking, these were predicted from spatially variable deposition [6]. If activity concentrations in biota were not available these were estimated using recommended CR values (for semi-natural pasture/heathland ecosystems) [7] and measured or estimated soil activity concentrations. Of the radionuclides considered in the FASSET framework, it was possible to estimate exposure to ${ }^{89} \mathrm{Sr},{ }^{90} \mathrm{Sr},{ }^{106} \mathrm{Ru},{ }^{134} \mathrm{Cs},{ }^{137} \mathrm{Cs},{ }^{238} \mathrm{Pu},{ }^{239} \mathrm{Pu},{ }^{241} \mathrm{Pu}$ and ${ }^{241} \mathrm{Am}$. Estimated doses were weighted assuming weighting factors of 10 for $\alpha$-radiation, 3 for low-energy $\beta$-radiation $(<10 \mathrm{keV})$, and 1 for $\beta$-radiation $(>10 \mathrm{keV})$ and $\gamma$-radiation. Where applicable, to estimate the external dose received by burrowing mammals it was assumed that small rodents spend $60 \%$ of their time underground and carnivorous mammals $40 \%$.

The CR values within the FASSET framework are not complete for all reference organism-radionuclide combinations. For this assessment, CR values were not available for: ${ }^{90} \mathrm{Sr}$ and ${ }^{106} \mathrm{Ru}$ for detritivorous and soil invertebrates; and bird egg, Pu isotopes for soil invertebrate and bird egg; and ${ }^{241} \mathrm{Am}$ for bird egg. To enable assessments for these reference organism - radionuclide combinations, the highest available CR values were used (an exception was that for actinide elements $\mathrm{CR}$ values for bird egg, the highest available values for mammalian reference organisms were assumed and not those for invertebrates) as recommended in the FASSET framework.

Doses were estimated for selected references/sampling sites from the available data to cover a range of reference organisms, observed effects and contamination levels. Estimates were made assuming mean and maximum observed/estimated activity concentrations in biota and soil. No studies reporting observations prior to 1988 were selected in an attempt to avoid the consequences of short-lived radionuclides and the passage of the contaminated air mass.

\section{COMPARING DOSE RATE ESTIMATES TO EFFECTS}

For small mammals, $\gamma$ - and high energy $\beta$-doses resulting from ${ }^{90} \mathrm{Sr}$ and radiocaesium contributed $>99 \%$ to the total estimated whole-body absorbed dose. The estimated contribution of internal dose to the total absorbed dose rate for small mammals was generally greater than that of external exposure (Tables 2-3). Alpha-doses contributed significant proportions of the estimated total dose received by invertebrate reference organisms (Table 4). 
Table 1 presents estimated dose rates for various entries from the collation of Sazykina et al. [5] comparing the reported biological effects for plants with summarised information from the FASSET framework [3]. The reported biological effects were observed within the range of estimated dose rates at which radiation induced effects may have been expected (on the basis of information summarised in the FASSET framework).

There are considerable data on biological effects observed in a range of rodent species in the compilation of Sazykina et al. [5]. Table 2 compares the potential range in dose rates estimated for 1988 with observed effects from Sazykina et al. [5] and summarised information from the FASSET framework [3]. For reasons of brevity, and the nature of how some observations have been reported, this comparison is presented for an area of $10 \mathrm{~km}$ radius around the Chernobyl plant. Where it is possible to comment, the observed effects are as would be expected, from the range of estimated dose rates and the FASSET summary of biological effects.

Table 1. Observed biological effects in plant species within the Chernobyl exclusion zone [5] compared to absorbed dose rates estimated using the FASSET framework and summarised biological effects [3].

\begin{tabular}{|c|c|c|c|c|}
\hline \multirow{2}{*}{$\begin{array}{c}\text { Species } \\
\text { (year observed) }\end{array}$} & \multicolumn{2}{|c|}{ Absorbed dose rate $\mu \mathrm{Gy} \mathrm{h}^{-1}$} & \multirow[t]{2}{*}{ Observed effects } & \multirow{2}{*}{$\begin{array}{c}\text { FASSET framework } \\
\text { summarised effects }\end{array}$} \\
\hline & Mean & Maximum & & \\
\hline $\begin{array}{c}\text { Arabidopsis thaliana } \\
\text { (mouseear cress) } \\
\text { (1988) }\end{array}$ & 5.7 & 11 & $\begin{array}{l}47 \pm 5.0 \% \text { of plants mutated } c f . \\
<5 \% \text { in unexposed populations }\end{array}$ & $\begin{array}{l}\left.\text { i) } 5.5 \mu \mathrm{Gy} \mathrm{h}^{-1}\right)- \\
\text { decreased seed } \\
\text { weight } \\
\text { ii) c. } 40 \mu \mathrm{Gy} \mathrm{h}^{-1} \text { - }\end{array}$ \\
\hline $\begin{array}{l}\text { Taraxacum officale } \\
\text { (dandelion) } \\
\text { (1988) }\end{array}$ & 33 & 170 & $\begin{array}{l}\text { Seed germination } 40+2.4 \% c f .94+2.5 \% \\
\text { for control }\end{array}$ & $\begin{array}{l}\text { increased mutation } \\
\text { rate in micro-satellite } \\
\text { DNA } \\
\text { iii) }>100 \mu \mathrm{Gy} \mathrm{h}^{-1}-\end{array}$ \\
\hline $\begin{array}{l}\text { Pinus sylvestris } \\
\text { (Scotch pine) } \\
(1990-91)\end{array}$ & 5.9 & 43 & $\begin{array}{l}56 \% \text { of pollen tubes branched and } 2 \% \\
\text { multi-branched } c f .29 \% \text { and } 0.1 \% \text { in } \\
\text { control samples }\end{array}$ & $\begin{array}{l}\text { morbidity responses } \\
\text { iv) } c .1000 \mu \mathrm{Gy} \mathrm{h}^{-1}- \\
\text { mortality (pines) }\end{array}$ \\
\hline
\end{tabular}

A series of studies investigating small mammal species within the Chernobyl exclusion zone conducted between 1994 and 1996 are reported by Baker and co-workers [9-12]. Table 3 presents estimated absorbed does rates for rodents at four of their study sites based predominantly on reported whole-body and soil activity concentrations [8]. Whilst the authors stated that there was little evidence to suggest persistent impaired performance of populations and communities [8], some biological effects, which may be attributable to exposure to ionising radiation, were reported [9-12]. The only morphological abnormality observed in small mammals $(n>300)$ collected at these sampling sites was an enlarged spleen in a few individuals and examination of karyotypes did not show gross chromosomal rearrangements [9]. Genetic diversity was significantly higher in the bank vole (Clethrionomys glareolus) population of the Red Forest site than at a reference site outside of the Chernobyl exclusion zone [11]; diversity was also greater at the Glyboke Lake site than at the reference site but this was not significant. Whilst this may have been the result of exposure to ionising radiation the authors noted that it may be the due to recolonisation from different founding populations; in 1986 reduced numbers of rodents had been recorded in some areas of the exclusion zone [5]. Mitochondrial DNA heteroplasmy (intra-individual DNA sequence variation) was compared in female Microtus arvalis (common vole) and their embryos from the Red Forest site and a control site [10]. Heteroplasmy levels were greater in the sample from the Red Forest but not significantly different to results for the control site. However, transversions and the presence of multiple base pair substitutions in a single fragment were only observed in the Red Forest sample. Mice and vole (Apodemus agrarius, Apodemus sylvaticus and C. glareolus) liver samples collected from these study sites in 1996 were analysed for oxidative stress enzyme activity [12]. Only A. agrarius demonstrated significantly reduced oxidative stress enzyme activity compared to animals collected from less contaminated areas. The authors make reference to studies which demonstrate the development of radioresistance in C. glareolus and A. sylvaticus within the Chernobyl zone and speculate that these 
species may have developed a higher radioresistance than A. agrarius. As for the comparisons within Tables 1 and 2, the observed effects reported for the sampling sites in Table 3 are as expected from the estimated dose rates and comparison with the FASSET effects summary (see Table 2).

Table 2. Summary of observed biological effects in rodent species within the Chernobyl exclusion zone [5] compared to absorbed whole-body dose rates estimated using the FASSET framework and summarised biological effects [3]. Observed data and dose rate predictions are for 1988; mean and range (in parenthesis) dose rates are estimated for area of $10 \mathrm{~km}$ radius around the Chernobyl plant.

\begin{tabular}{|c|c|c|c|}
\hline \multicolumn{2}{|c|}{ Absorbed dose rate $\left(\mu G y h^{-1}\right)$} & Observed effects & $\begin{array}{l}\text { FASSET framework summarised } \\
\text { effects }\end{array}$ \\
\hline Internal & $\begin{array}{c}41 \\
(0.09-770)\end{array}$ & $\begin{array}{l}\text { i) Liver abnormalities in a few animals (more } \\
\text { abnormalities were observed in } 1986 / 87 \text { ) }\end{array}$ & $\begin{array}{l}\text { i) Growth (rat) not affected at } \\
16 \mu \mathrm{Gy} \mathrm{h} \mathrm{h}^{-1} \text { (affected at }>3000\end{array}$ \\
\hline External & $\begin{array}{c}8.1 \\
(0.02-200)\end{array}$ & $\begin{array}{l}\text { ii) Leucocyte concentrations lower than in control } \\
\text { animals }\end{array}$ & $\begin{array}{l}\left.\mu \mathrm{Gy} \mathrm{h}^{-1}\right) \\
\text { ii) } 180-850 \mu \mathrm{Gy} \mathrm{h}^{-1} \text { some blood }\end{array}$ \\
\hline Total & $\begin{array}{c}49 \\
(0.1-980)\end{array}$ & 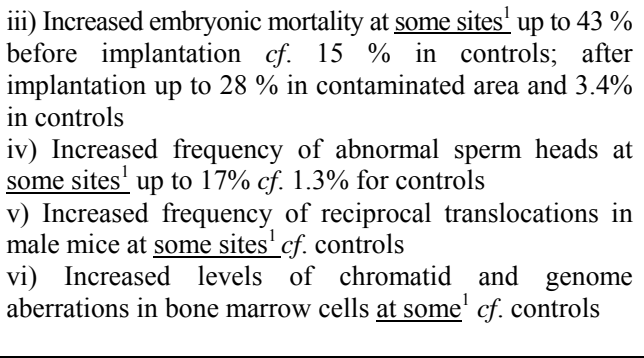 & $\begin{array}{l}\text { parameters affected } \\
\text { iii) No effect on thyroid function } \\
\text { at } c .10^{4} \mu \mathrm{Gy} \mathrm{h} \mathrm{h}^{-1} \\
\text { iv) No effect lifespan (mice) - } \\
460 \mu \mathrm{Gy} \mathrm{h}^{-1}, \quad \text { (significant } \\
\text { reductions }>c .10^{3} \mu \mathrm{Gy} \mathrm{h}^{-1} \text { (mice, } \\
\text { goat, dog)) } \\
\text { v) c. } 100 \mu \mathrm{Gy} \text { threshold for } \\
\text { reproductive effects } \\
\text { vi) Mutation LOEDR }{ }^{2}>420 \mu \mathrm{Gy} \\
\mathrm{h}^{-1} \text { (mice) }\end{array}$ \\
\hline
\end{tabular}

${ }^{1}$ No significant differences were observed for these parameters at other sites studied within the Chernobyl exclusion zone compared with controls; ${ }^{2}$ LOEDR - lowest observed effect dose rate.

Table 3. Estimated mean and maximum absorbed dose rates for rodents at sites described by Chesser et al. [8] and Baker et al. [9].

\begin{tabular}{lccc}
\hline Site & \multicolumn{3}{c}{ Estimated absorbed dose rate mean $\left(\right.$ maximum) $\mu G y h^{-1}$} \\
& Internal & External & Total \\
\hline Chistogalovka & $5.3(47)$ & $12(18)$ & $\mathbf{1 7}(\mathbf{6 5 )}$ \\
Glyboke Lake & $94(1150)$ & $17(17)$ & $\mathbf{1 1 1}(\mathbf{1 1 7 0 )}$ \\
Red Forest & $214(3320)$ & $26(37)$ & $\mathbf{2 4 1}(\mathbf{3 3 6 0})$ \\
Orchard & $8.6(11)$ & $3.5(5.2)$ & $\mathbf{1 2 ( 1 7 )}$ \\
\hline
\end{tabular}

Gilhen et al. [13] report studies at a number of sites within the Chernobyl exclusion zone conducted between 2000 and 2003. Estimated absorbed dose rates to rodent species at their most contaminated site were the highest estimated for the data considered within this assessment (Table 4). A significant increase in mitotic index for C. glareolus was recorded at this and other sites, which was related to increasing contamination level. Whilst no differences in rodent reproductive organ or spleen size compared with control sites were observed, post-mortem examination of C. glareolus specimens found some individuals exhibiting epithelial metaplasia and hyperplasia, and small aggregations of lymphocytes [13]. Measurements of soil biological activity at this site, measured using bait lamina which predominantly reflect the biological activity of soil invertebrates, were significantly lower than at less contaminated sites [13]. The summary of effects data in the FASSET framework contained too few data for invertebrate species to comment on the impact of chronic doses in the range estimated here. Table 4 presents estimated mean absorbed dose rates for all FASSET reference organisms at this site. Dose rates for detritivorous invertebrates and burrowing mammals were estimated using measured whole-body ${ }^{137} \mathrm{Cs}$ and ${ }^{90} \mathrm{Sr}$ activity concentrations. For comparison to the other reference organisms, if recommended CR values had been used to derive dose rates, the resultant estimates would have been circa 2 and 4-fold higher for detritivorous invertebrates and burrowing mammals 
respectively. Estimated mean dose rates for most mammalian reference organism are in excess of those above which we may expect shortening of life, reduced growth rates and impacts on reproduction to occur [3]. Dose rates estimated for plant reference organisms are sufficient that some reproductive, mutation and morbidity responses may be predicted (cf. Table 2 ). There are too few effects data for the remaining reference organisms to enable comment [3].

Table 4. Mean estimated absorbed dose rates for all FASSET reference organisms assuming soil activity concentrations for the most contaminated site of Gilhen et al. [13] in 2003.

\begin{tabular}{|c|c|c|c|c|c|}
\hline Reference organism & $\begin{array}{l}\text { Detritivorous } \\
\text { invertebrate }\end{array}$ & Soil invertebrate & $\begin{array}{c}\text { Burrowing } \\
\text { mammal }\end{array}$ & $\begin{array}{c}\text { Small } \\
\text { herbivorous } \\
\text { mammal }\end{array}$ & $\begin{array}{c}\text { Large } \\
\text { herbivorous } \\
\text { mammal }\end{array}$ \\
\hline Representative geometry & Woodlouse & Earthworm & Mouse & Rabbit & Roe deer \\
\hline Absorbed dose rate $\left(\mu \mathrm{Gy} \mathrm{h}^{-1}\right)$ & 569 & 1938 & 603 & 3100 & 2932 \\
\hline $\begin{array}{l}\text { Percentage of total absorbed } \\
\text { dose rate from } \alpha \text {-radiation }\end{array}$ & $25 \%$ & $7 \%$ & $0.4 \%$ & $<0.01 \%$ & $0.1 \%$ \\
\hline Reference organism & $\begin{array}{c}\text { Small } \\
\text { carnivorous } \\
\text { mammal }\end{array}$ & $\begin{array}{l}\text { Large carnivorous } \\
\text { mammal }\end{array}$ & Bird egg & $\begin{array}{l}\text { Herb/ } \\
\text { Shrub }^{1}\end{array}$ & Tree \\
\hline Representative geometry & Weasel & Fox & & & \\
\hline Absorbed dose rate $\left(\mu \mathrm{Gy} \mathrm{h}{ }^{-1}\right)$ & 3100 & 3763 & 189 & 343 & 281 \\
\hline $\begin{array}{l}\text { Percentage of total absorbed } \\
\text { dose rate from } \alpha \text {-radiation }\end{array}$ & $<0.01 \%$ & $<0.01 \%$ & $1 \%$ & $\mathrm{n} / \mathrm{a}$ & $\mathrm{n} / \mathrm{a}$ \\
\hline
\end{tabular}

${ }^{1}$ Estimated dose rates are the same for these two reference organisms; n/a - not applicable as only external doses estimated.

\section{DISCUSSION}

The dose rates estimated using the methodology presented in the FASSET framework for some reference organisms at some sampled sites within the Chernobyl exclusion zone are sufficient to predict that some biological effects may occur on the basis of the FASSET summaries [3]. Although paucity of observations under conditions of chronic irradiation makes direct comparison difficult, the biological effects observed in the Chernobyl exclusion zone over the period considered here (1988-2003) are broadly in agreement with those which may have been expected. However, we should acknowledge that the summary of radiation effects within the FASSET framework [3] include some observations from the Chernobyl exclusion zone which may relate to the same original Russian language works as collated by Sazykina et al. [5].

It was not possible to assess all of the radionuclides which biota may be exposed to within the Chernobyl exclusion zone, either because the FASSET framework does not consider them (e.g. $\left.{ }^{154} \mathrm{Eu}\right)$ or due to a lack of deposition data. However, the few available measurements for some of the nuclides not considered suggest that their contributions to doses would be low.

Estimates of absorbed dose rates to large mammalian reference organisms in Table 5 are in excess of that at which mutations, shortening of life, reduced growth rates or impacts on reproduction may be expected. However, few, if any, studies have considered radiation effects in large wild mammals inhabiting the exclusion zone. From reported measurements of ${ }^{90} \mathrm{Sr}$ and ${ }^{137} \mathrm{Cs}$ activity concentrations in large herbivorous and carnivorous mammals sampled throughout the exclusion zone (1988-2000) [6], mean absorbed dose rates from internal exposure of 2.3 and $9.2 \mu \mathrm{Gy} \mathrm{h}^{-1}$ respectively can be estimated; maximum estimates are 10 and $95 \mu \mathrm{Gy} \mathrm{h}^{-1}$ respectively.

The FASSET framework does not consider all organism types, birds and reptiles are notable exceptions which may require assessment under environmental protection legislation in many countries [e.g. 4]. Increased albinism, depressed immunoglobulin levels and reduced populations 
(between 1986 and 1996) were reported for barn swallows (Hirado rustica) in the Chernobyl exclusion zone $[14,15]$. Reported whole-body ${ }^{90} \mathrm{Sr}$ and ${ }^{137} \mathrm{Cs}$ activity concentrations in Lacerta agilis (sand lizard) samples from one of the sites studied by Gilhen et al. [13] suggest dose rates comparable to those estimated above for rodents for this reptilian species.

We should acknowledge that probably the largest overall impact of the Chernobyl accident on the ecology of the exclusion zone was brought about by the removal of the human population with the consequent cessation of activities such as agricultural production and the associated use of herbicides, pesticides and fertilisers. As a result floral and faunal biodiversity and abundance has increased considerably [16]. However, as demonstrated above, effects characteristic of those expected from chronic exposure to ionising radiation continue to be observed. Estimated doses are considerably in excess of international guidelines in some areas (e.g. the IAEA [17] suggest that limits of 1 or $10 \mathrm{mGy} \mathrm{d}^{-1}$ should not result in harm for terrestrial animal and plant populations respectively) and are, in some cases, greater than thresholds above which shortening of life may be expected. The available data for the Chernobyl exclusion zone allows some comparison of predicted and observed biological effects. However, the impacts of radiation at all ecosystem levels (genetic to ecological community composition and diversity) need to be quantified simultaneously. The Chernobyl exclusion zone provides one of the few environments where these questions can be addressed.

\section{Acknowledgements}

This work was supported by the EC-EURATOM $6^{\text {th }}$ Framework Programme (2002-2006) and forms part of the ERICA project, contract FI6R-CT-2003-508847. It utilises outputs from the EC $5^{\text {th }}$ Framework Programme FASSET [FIGE-CT-2000-00102] and EPIC [ICA2-CT-2000-10032] projects. The financial support of the EC is gratefully acknowledged and CEH are grateful for the co-funding received from the England and Wales Environment Agency. Funding for the Ukrainian co-author was provided by the UK Royal Society.

\section{References}

[1] United States Department of Energy, A graded approach for evaluating radiation doses to aquatic and terrestrial biota. DOE-STD-1153-2002, (USDoE, Washington, 2002).

[2] D. Copplestone, S. Bielby, S.R. Jones, D. Patton, P. Daniel, I. Gize, Impact Assessment of Ionising Radiation on Wildlife, R\&D Publication 128, (EA, Bristol, 2001).

[3] C-M. Larsson, C. Jones, J.M. Gomez-Ros, I. Zinger, (editors), Framework for assessment of environmental impact of ionising radiation in major European ecosystems, deliverable for the EC Project FIGE-CT-2000-00102 (FASSET), (SSI, Stockholm, 2004).

[4] D. Copplestone, M.D. Wood, S. Bielby, S.R., Jones, J. Vives, N. A. Beresford, Habitat regulations for Stage 3 assessments: radioactive substances authorisations, R\&D Technical Report P3-101/SP1a, (EA, Bristol, 2003).

[5] T.G. Sazykina, A. Jaworska, J. Brown, (editors), Dose effects relationships for reference (or related) Arctic biota, deliverable for the EC Project ICA2-CT-2000-10032 (EPIC), (NRPA, Østerås, 2003).

[6] N.A. Beresford, S.M. Wright, C.L. Barnett, M.D. Wood, S. Gaschak, A. Arkhipov, T.G. Sazykina, R. Avila, Radioprotection (colloques), this issue, submitted.

[7] J. Brown, P. Strand A. Hosseini, P. Børretzen (editors), Handbook for assessment of the exposure of biota to ionising radiation from radionuclides in the environment, deliverable for the EC Project FIGE-CT-2000-00102 (FASSET), (NRPA, Østerås, 2003).

[8] R.K. Chesser, D.W. Sugg, M.D. Lomakin, R.A. Van Den Bussche, A.J. DeWoody, C.H. Jagoe, C.E. Dallas, F.W. Whicker, M.H. Smith, S.P. Gaschak, I.V. Chizhevsky, V.V. Lyabik, E.G. Buntova, K. Holloman, R.J. Baker, Env. Toxicol. Chem., 19, 305 (2000). 
[9] R.J. Baker, M.J. Hamilton, R.A. Van Den Bussche, L.E. Wiggins, D.W. Sugg, M.H. Smith, M.D. Lomakin, S.P. Gaschak, E.G. Buntova, G.A. Rudenskaya, R.K Chesser, J. Mammal, 77, 155 (1996). [10] R.J. Baker, J.A. Dewoody, A.J. Wright, R.K. Chesser, Ecotoxiology, 8, 301 (1999).

[11] C.W. Matson, B.E. Rodgers, R.K. Chesser, R.J. Baker, Env. Toxicol. Chem., 19, 8, 2130 (2000).

[12] K.A. Holloman, C.E. Dallas, C.H. Jagoe, R. Tackett, J.A. Kind, E.A. Rollor, Toxicol. Chem., 19, 11,2830 (2000).

[13] M. Gilhen, K. Cooper, K. Radbourne, \& R. Carrington, MSc. theses, University of Liverpool. (2001-2003).

[14] H. Ellegren, G. Lindgram, C.R. Primmer, A.P. Møller. Nature, 389, 593 (1997).

[15] A. Camplani, N. Saino, A.P. Møller, Proc. R. Soc., 266, 1111 (1999).

[16] R.J. Baker, R.K. Chesser, Env. Toxicol. Chem., 19, 1231 (2000).

[17] IAEA, Effects of ionising radiation on plants and animals at levels implied by current radiation protection standards, TRS 332, (IAEA, Vienna, 1992). 